\title{
O homem e o mar: Emir Suaiden e o Instituto Brasileiro de Informação em Ciência e Tecnologia
}

Luciana Ferreira da Costa

Professora do Departamento de Ciência da Informação da Universidade Federal da Paraíba. Mestre em Ciência da Informação pela Universidade Federal da Paraíba.

Guilherme Ataíde Dias

Professor do Departamento de Ciência da Informação da Universidade Federal da Paraíba. Doutor em Ciências da Comunicação pela Universidade de São Paulo.

Antonio Lisboa Carvalho de Miranda

Diretor da Biblioteca Nacional de Brasília e do Programa dos Livros e da Leitura do Distrito Federal. Responsável pelo Sistema de Bibliotecas do Distrito Federal. Doutor em Ciências da Comunicação pela Universidade de São Paulo.

Emir José Suaiden

Diretor do Instituto Brasileiro de Informação em Ciência e Tecnologia. Professor do Departamento de Ciência da Informação e Documentação da Universidade de Brasília. Doutor em Ciências da Informação pela Universidad Complutense de Madrid, Espanha. Pós-Doutor pela Universidad Carlos III de Madrid, Espanha. 
O homem e o mar: Emir Suaiden e o Instituto Brasileiro de Informação em Ciência e Tecnologia
Luciana Ferreira da Costa; Guilherme Ataíde Dias; Antonio Lisboa Carvalho de Miranda; Emir José Suaiden

Homem livre, o oceano é um espelho fulgente Que tu sempre hás de amar. No seu dorso agitado, Como em puro cristal, contemplas, retratado, Ter íntimo sentir, teu coração ardente.

Charles Baudelaire

\section{Primeiras palavras sobre o homem}

Emir Suaiden é um dos decanos da Biblioteconomia e da Ciência da Informação no Brasil e na região ibero-americana. Acompanho a trajetória profissional do atual líder do Instituto Brasileiro de Informação em Ciência e Tecnologia (IBICT) há décadas, com crescente admiração por sua capacidade empreendedora. Desde os tempos do Instituto Nacional do Livro (INL), plantando bibliotecas em todo o país, formando pessoal para o desempenho das atividades, conforme os paradigmas ditados pela Unesco e devidamente atualizados e ambientados no Brasil. Afinal, o Brasil já havia avançado muito na área da "informação para o desenvolvimento" (era o mote dos anos 70) e estava à frente dos países ibero-americanos em pesquisa e em pós-graduação no nosso campo de conhecimento. Todo mundo sabe o que aconteceu: veio o vendaval da (felizmente curta) era Collor, fecharam o INL e o sistema de bibliotecas públicas desandou por muitos anos.

Depois dos cursos de Mestrado em Biblioteconomia e Doutorado em Ciências da Informação que Emir Suaiden fez, respectivamente, na Universidade Federal da Paraíba (UFPB) e na Universidad Complutense de Madrid, ele voltou a atuar pelo desenvolvimento do setor de informação. Desde os tempos em que foi Presidente da Associação dos Bibliotecários do Distrito Federal (ABDF), depois como professor da Universidade de Brasília (UnB) - onde permanece, depois de chegar ao topo da carreira como Professor Titular - e atualmente no IBICT. Some-se ao seu currículo, posteriormente, o pós-doutoramento realizado pela Universidad Carlos III de Madrid. É justo reconhecer que ele avançou no campo da inclusão e da alfabetização digital de usuários, sendo pioneiro com sua (então) orientanda Cecília Leite, autores que foram de um inovador projeto numa escola de Brasília (GISNO) que - coisa rara entre nós chegou a virar lei para levar a experiência a outros estabelecimentos de ensino do Distrito Federal, também um prêmio.

Esteve no comando do FAP - o programa de apoio à pesquisa da Capital Federal, onde apoiou e promoveu não apenas projetos de pesquisa como a inclusão social, o que o levou, por sondagem nacional, ao IBICT, depois reconduzido ao posto por mérito.

Sempre estivemos associados em atividades profissionais organização de eventos científicos, publicações profissionais - e no desenvolvimento de projetos importantes. O último deles mostra perfeitamente a evolução do trabalho de Emir Suaiden ao promover a instalação e inauguração da Biblioteca Nacional de Brasília, desde 2007, mediante um generoso convênio do Ministério da Ciência e Tecnologia (MCT) com o Governo de Brasília (DF), com o apoio da Rede Nacional de 
Pesquisa (RNP). A adesão de Emir Suaiden e de Cecília Leite foi fundamental para que nós concluíssemos as obras de instalação física e toda a tecnologia necessária a um projeto ambicioso e renovador como o da Biblioteca Nacional de Brasília (BNB) que, lamentavelmente, sofreu graves atrasos em sua continuidade depois da crise que desestabilizou o governo local; mas continuamos empenhados em superar e avançar na consolidação de nossa biblioteca híbrida, para o atendimento da população brasiliense e o público nacional e internacional pela internet e por outros meios de comunicação.

Este texto serve de apresentação da excelente entrevista realizada com o nosso amigo Emir Suaiden, sob idealização e organização da Profa. Luciana Costa com a colaboração do Prof. Guilherme Dias, ambos do Departamento de Ciência da Informação da UFPB. É apenas para qualificar o entrevistado que, mesmo dispensando apresentação, é sempre bom fazer o devido reconhecimento por sua longa trajetória profissional, intelectual e humana.

Brasília, 12 de março de 2011. Antonio Lisboa Carvalho de Miranda

\section{Memórias, contos e ensinamentos do mar}

Entrevistado: Prof. Emir José Suaiden

Entrevistadores: Profa. Luciana Ferreira da Costa e Prof. Guilherme Ataíde Dias

Profa. Luciana Costa - De início, uma questão muito particular. O que representa para o senhor, Professor Emir, a direção da mais importante instituição dedicada à informação científica e tecnológica do país, o Instituto Brasileiro de Informação em Ciência e Tecnologia (IBICT), e ainda pelo segundo mandato?

Prof. Emir Suaiden - Dirigir o IBICT é uma grande honra. É alcançar o topo na carreira da Ciência da Informação. E isso para mim é ainda mais expressivo, pois tive o privilégio de ser funcionário, usuário e agora diretor deste Instituto. Ter sido reconduzido ao cargo foi gratificante para mim, vez que estou tendo a oportunidade de acompanhar de perto o desdobramento daquilo que plantamos no primeiro mandato. Na seleção para o cargo, preparei um documento intitulado "Visão de Futuro", no qual apontei alguns caminhos para o IBICT dialogar mais com a sociedade e entrar para a agenda do governo. Propusemos a criação do Programa Inclusão Social, o qual se consolidou e o IBICT passou a empregar a sua tradicional experiência em trabalhar a informação em prol da inclusão social. Ação que denominamos inclusão informacional.

Prof. Guilherme Dias - Na perspectiva, portanto, da visão de futuro deste instituto que está prestes a completar 57 anos no dia 04 de março de 2011, como se atualiza a missão do IBICT em face dos novos 
cenários de globalização e das tecnologias de informação e comunicação no século XXI?

Prof. Emir Suaiden - Em 2005, logo que assumi a direção do IBICT, fizemos uma revisão da missão institucional. A intenção foi justamente essa: atualizá-la para fazer face às novas exigências da sociedade. A missão incorporou, então, a ideia de socialização e integração do conhecimento, o que gerou grandes transformações. Criamos novos serviços de informação e reavaliamos os existentes, a fim de identificar veios sociais naqueles que poderiam contribuir com esse novo cenário. Quanto aos novos serviços, a primeira iniciativa foi criar a revista Inclusão Social e o Mapa da Inclusão Digital no Brasil, que hoje possuem grande aceitação pela comunidade usuária. Quanto aos serviços tradicionais, legado que recebi, cito como exemplo o Canal Ciência, portal de divulgação científica, que ampliou suas ações educativas com o propósito de trabalhar junto a educadores e estudantes do ensino médio e técnico, atendendo a uma nova demanda educacional, que é a integração de professores e alunos às novas tecnologias de informação; outro exemplo é o projeto Avaliação do Ciclo de Vida de Produtos (ACV), que além de atender o seu principal público, as indústrias, interage agora com jovens estudantes por meio de cartilhas e jogos eletrônicos educativos, especialmente voltados ao ensino fundamental no intuito de apoiar o desenvolvimento de uma geração mais consciente no plano ambiental; e terceiro é o fortalecimento do movimento do livre acesso à informação científica e tecnológica. É importante observar que todo esse esforço, aliado às atividades do IBICT de repasse gratuito de tecnologias de informação, propicia o aumento da oferta de informação científica e tecnológica brasileira na Internet. Falando em tecnologias da informação, acho importante mencionar a criação da Biblioteca Nacional de Brasília, a BNB, na qual o IBICT teve uma participação determinante. Nela, além do uso de metodologias próprias, desenvolvidas por nossa equipe juntamente com pedagogos da BNB, foram utilizados recursos tecnológicos de ponta, em parceria com a RNP, para criar espaços sociais inovadores dedicados a estudos e debates. Construímos, assim, uma biblioteca híbrida, onde acervos físicos e eletrônicos se integram, oferecendo um serviço diferenciado ao usuário. Isto é, um serviço que possibilita tanto o acesso físico quanto virtual a conteúdos diversificados, em especial científicos e tecnológicos, sempre com o compromisso de promover a inclusão informacional e digital do cidadão. Diante dessas e outras ações, arriscaria dizer que o IBICT reúne, hoje, todas as condições para implantar a sociedade da informação no Brasil. E já estamos caminhando nessa direção por meio de várias ações. Uma delas é a recente junção de esforços entre o IBICT, a Fundação Biblioteca Nacional, o Ministério da Cultura (MinC), a Federação Brasileira de Associações de Bibliotecários, Cientistas da Informação e Instituições (Febab) e o Conselho Federal de Biblioteconomia (CFB) para elaborar um projeto de capacitação de bibliotecários e assistentes de 1.280 bibliotecas públicas brasileiras no uso 
das tecnologias de informação e comunicação. Esperamos, com isso, fortalecer essas bibliotecas pela melhoria do atendimento aos seus usuários e pelo estímulo de seu uso pelas comunidades locais.

Profa. Luciana Costa - Tratando de novos cenários e em face do senhor ter citado a consolidação da pretensão do IBICT de dialogar mais com a sociedade e entrar para a agenda do governo, qual a importância do instituto diante dos desafios do governo da Presidente Dilma Rousseff com a colaboração do Ministro da Ciência e Tecnologia Aloísio Mercadante?

Prof. Emir Suaiden - A preocupação do ministro com a esfera social é percebida em todas as suas falas. O desejo dele converge com o nosso, que é o de que a informação produzida pelas pesquisas científicas e tecnológicas do país chegue a todos os brasileiros. E a importância do IBICT diante dos desafios do ministro Mercadante reside no fato do Instituto ser um órgão nacional de informação compromissado com a popularização da ciência e tecnologia. Portanto, é grande a nossa responsabilidade nesse processo. $\mathrm{E}$, a meu ver, o IBICT pode contribuir em dois aspectos fundamentais: no combate à desinformação e à manipulação da informação, por meio do uso de técnicas de inclusão informacional; e no fortalecimento do ensino fundamental por meio da proposição de políticas de informação com os olhos voltados à construção de uma sociedade da informação onde o pesquisador seja formado desde o início de sua educação, e não apenas nos estudos avançados, como acontece hoje. Ou seja, para alavancar o surgimento de uma nova geração de pesquisadores é preciso despertar nos jovens, desde cedo, o interesse pela ciência, tecnologia, arte e cultura. Com relação a isso, já temos algumas iniciativas. Promovemos cursos de alfabetização digital diferenciada para professores do ensino fundamental e médio de escolas rurais e indígenas, onde são capacitados a saber buscar e usar a informação. Os professores aprendem a utilizar ferramentas tecnológicas para produzir conteúdos próprios e para estimular seus alunos a se tornarem também autores. Trata-se de uma iniciativa de inclusão digital básica com o diferencial de agregar metodologias pedagógicas para possibilitar a inclusão informacional. A metodologia empregada teve ampla aceitação e está sendo replicada em outras comunidades rurais e indígenas. Em diversos casos, o modelo proposto despertou nos professores a realização de eventos criativos que ultrapassaram os limites das escolas, envolvendo famílias de alunos e comunidades locais, demonstrando ser um poderoso recurso de desenvolvimento social local.

Prof. Guilherme Dias - Sobre os atuais produtos e serviços do IBICT, além dos já citados, gostaríamos que o senhor comentasse as principais frentes de atuação nacional. 
Prof. Emir Suaiden - Além das frentes de atuação que mencionei anteriormente, estamos investindo na construção de repositórios institucionais de acesso livre em universidades e instituições públicas de pesquisa, para facilitar o registro e a disseminação da memória institucional em meio digital e aumentar o acesso à informação científica e tecnológica. Temos, ainda, o portal Canal Ciência que se transformou em um relevante veículo de divulgação de pesquisas brasileiras em linguagem acessível a estudantes e à sociedade em geral. Outros dois serviços que merecem destaque são o Sistema de Editoração Eletrônica de Revistas (SEER) e a Biblioteca Digital Brasileira de Teses e Dissertações (BDTD). Nos últimos quatro anos, o SEER já criou mais de mil revistas eletrônicas em todo o Brasil - muitas das quais estão bem classificadas no programa Qualis da Capes. Não podendo deixar de citar, nesse contexto, o legado da revista Ciência da Informação, além da já citada revista Inclusão Social, e, mais recentemente, a parceria da Universidade Federal do Rio de Janeiro com o IBICT para publicação do periódico Liinc em Revista e a cooperação científica do IBICT com a UFPB para a publicação da Revista Perspectivas em Gestão \& Conhecimento. Sobre a BDTD, esta já conta, hoje, com um acervo de quase cento e sessenta mil registros, o que faz dela a segunda maior biblioteca digital de teses e dissertações do mundo. Finalmente, vale registrar que criamos o primeiro curso de pós-doutorado em ciência da informação no Brasil, em nossa unidade de ensino no Rio de Janeiro, em convênio com a Universidade Federal do Rio de Janeiro (UFRJ). Registrando que o Programa de Pós-Graduação em Ciência da Informação mantido pelo IBICT, hoje em convênio com a UFRJ, tem origens nos primeiros cursos de especialização ofertados pelo Instituto na década de 50 ainda sob nomenclatura de Instituto Brasileiro de Bibliografia e Documentação (IBBD). Penso que tudo isso contribuiu para os resultados da crescente visibilidade do IBICT em nível nacional e internacional. Em janeiro de 2011, o Ranking Web, elaborado pelo Laboratório de Cibermetria do Consejo Superior de Investigaciones Científicas (CSIC), da Espanha, classificou o IBICT em sexto lugar entre os centros de pesquisa mais importantes do Brasil na Web e em $154^{\circ}$ do mundo.

Profa. Luciana Costa - Falando em repercussão internacional, a respeito da representação e cooperação do IBICT com outros países, quais as principais ações, Prof. Emir, o senhor destacaria?

Prof. Emir Suaiden - A área de cooperação internacional do IBICT é bastante pró-ativa. Ela permeia a maioria das atividades do Instituto, vez que quase todos os nossos projetos, produtos e serviços têm algum componente internacional. Alguns acordos já existem há muitos anos. É o caso do International Standard Serial Number (ISSN), do Programa de Comutação Bibliográfica (COMUT) e da Classificação Decimal Universal (CDU). Como principais ações de cooperação internacional, vale destacar: o compromisso conjunto de propor eventos e metodologias para combater 
a exclusão digital na região ibero-americana - em acordo firmado com a Universidad de Costa Rica e a Universidad Carlos III, de Madrid; a implantação no Brasil do pensamento do Ciclo de Vida com base em padrões internacionais, que engloba várias ações, como o desenvolvimento de ontologias, sistemas de informação, cartilhas e jogos eletrônicos educativos, além do próprio inventário brasileiro do Ciclo de Vida de Produtos, objeto principal do Programa ACV - em parceria com a Comunidade Européia, o Forschungszentrum Karlsruhe (FZK) da Alemanha, o Programa das Nações Unidas para o Meio Ambiente (PNUMA) e com várias universidades, especialmente latino-americanas; a integração do Repositório Científico de Acesso Aberto de Portugal (RCAAP) e o OASIS.br (sistema do IBICT), para reforçar a presença da língua portuguesa na sociedade da informação - em cooperação com o Ministério da Ciência, Tecnologia e Ensino Superior de Portugal; a implantação no Brasil do Programa Informação para Todos (IFAP) - em cooperação com a UNESCO. Por meio deste acordo, O IBICT foi nomeado Coordenador do Comitê Nacional do Programa, sendo seu diretor o representante brasileiro no Bureau internacional do IFAP; o apoio a publicações e atividades de disseminação de novos conhecimentos brasileiros, por meio da melhoria da pesquisa, do desenvolvimento e da implementação e suporte de software abertos - em acordo firmado com o Public Knowledge Project $(\mathrm{PKP})$, da University of British Columbia, Canadá; e as pesquisas conjuntas na área de biblioteconomia para compartilhar descobertas com a comunidade bibliotecária mundial - por meio de acordo que estabelece o vínculo do IBICT com a International Federation of Library Association (IFLA). E, mais recentemente, fizemos um mapeamento junto às coordenações do IBICT para identificar temas que poderiam ser ampliados e fortalecidos por meio de novos acordos e ações de cooperação internacional. Foram identificados como prioritários a preservação digital, a linguagem clara e o livre acesso à informação.

Prof. Guilherme Dias - Neste contexto, como o senhor avalia a interlocução ou reciprocidade entre o IBICT e, principalmente, as universidades e o setor industrial e empresarial?

Prof. Emir Suaiden - Hoje, o IBICT e a universidade brasileira caminham juntos. Nossa atuação nas universidades é principalmente a de fortalecer suas bibliotecas, por meio da implantação de repositórios digitais, do estímulo à criação de publicações eletrônicas e pela transferência de tecnologia utilizada na BDTD. Por outro lado, vários professores pesquisadores das universidades estão presentes em praticamente todos os projetos do IBICT. No que tange à relação do setor industrial e empresarial com a universidade, o IBICT tem liderado ações, especialmente no campo das tecnologias de informação, que aproximam esses dois setores ao conhecimento gerado em universidades e instituições de pesquisa. Exemplo disso é o Serviço Brasileiro de Respostas Técnicas (SBRT), onde diversos institutos de pesquisa 
colaboram para oferecer soluções tecnológicas a empreendedores e micro e pequenas empresas. Outro exemplo é o programa ACV, citado anteriormente, que conta com a parceria da iniciativa privada, de universidades e institutos de pesquisa. Nesse programa estão sendo desenvolvidos Inventários do Ciclo de Vida de Produtos que visam alinhar os processos de gestão industrial aos padrões internacionais de proteção ambiental.

Profa. Luciana Costa - Diante da contribuição do IBICT para o desenvolvimento da área da Ciência da Informação no Brasil, como vem sendo realizado o diálogo com a Federação Brasileira de Associações de Bibliotecários, Cientistas da Informação e Instituições (FEBAB), a Associação Nacional de Pesquisa e Pós-Graduação em Ciência da Informação (ANCIB) e com as instituições oficiais de avaliação e financiamento da pós-graduação e da pesquisa no país, como a Coordenação de Aperfeiçoamento de Pessoal de Nível Superior (CAPES) e o Conselho Nacional de Desenvolvimento Científico e Tecnológico (CNPq)?

Prof. Emir Suaiden - O diálogo com as associações de classe como a Ancib e a Febab tem sido excelente. O IBICT vem contribuindo ativamente com a realização do Encontro Nacional de Pesquisa em Ciência da Informação (Enancib). Organizamos a versão de 2010 do evento e já está estamos em contato com a UnB para contribuir com a realização do Enancib 2011. No que diz respeito à Febab, estamos em constante diálogo para a realização do próximo Congresso Brasileiro de Biblioteconomia, Documentação e Ciência da Informação (CBBD) em Maceió. Quanto às relações com a Capes e o CNPq, estamos trabalhando para melhorar o acesso à informação em ciência e tecnologia. Junto à Capes, estamos propondo a incorporação de um link ao Comut e ao Portal de Periódicos da Capes, para possibilitar o acesso a coleções retrospectivas (isto é, aquelas com mais de cinco anos). No caso do CNPq, estamos negociando a inserção da BDTD na Plataforma Lattes, de forma a interrelacionar o currículo do pesquisador com a sua tese ou dissertação. Quanto ao financiamento da pesquisa, temos várias pesquisas e projetos executivos amparados por recursos da Financiadora de Estudos e Projetos (FINEP), empresa pública vinculada ao Ministério da Ciência e Tecnologia, recursos esses que, muitas vezes, são mais expressivos do que os próprios recursos orçamentários do Instituto.

Prof. Guilherme Dias - Por fim, Prof. Emir, gostaríamos que o senhor comentasse as perspectivas futuras da Ciência da Informação no Brasil e pedimos que deixe uma mensagem aos profissionais dedicados à área.

Prof. Emir Suaiden - No mundo ibero-americano, a ciência da informação teve seu desenvolvimento maior no Brasil, México e Espanha, sendo a qualidade dos profissionais da informação no Brasil altamente 
considerada por todos. Constata-se isso nos nossos cursos de pósgraduação, que formam profissionais muito respeitados internacionalmente, sempre bem colocados no mercado de trabalho e bastante procurados por setores que primam pela excelência intelectual. Essa competência está refletida também na expressiva e relevante produção científica nacional. Isso é fato incontestável. É fato também que a revolução tecnológica facilitou o trabalho desses profissionais, por meio da construção de bibliotecas digitais, periódicos eletrônicos e da oferta de informação em tempo real. Contudo, na minha leitura, essa facilidade só pode ser obtida porque esses profissionais, a que me referi anteriormente, se capacitaram nas tecnologias e provocaram, juntamente com profissionais da área de informática, essa revolução tecnológica. É um ciclo calcado na competência. Levando em consideração que o momento exige que voltemos todas as nossas atenções à redução do gap existente entre conhecimento e políticas públicas, a minha mensagem aos profissionais de informação é simples: devemos sempre buscar demonstrar a importância da informação profissionalmente trabalhada, de forma que as questões inerentes ao setor de informação entrem definitivamente na agenda do governo e que as estruturas informacionais se tornem cada vez mais visíveis para a população brasileira. É claro que grandes desafios aparecerão nesse caminho, mas eles poderão ser superados por profissionais competentes, bem preparados e de olhos voltados a questões como o livre acesso à informação, alfabetização informacional e à construção de uma efetiva sociedade da informação.

Entrevista concedida por Emir José Suaiden a Luciana Ferreira da Costa e Guilherme Ataíde Dias em 28 de fevereiro de 2011. 